\title{
Mere moments
}

"I need to talk to you" not do you have a moment, or when you have a second, "we are about to have a code blue"

It's a young woman, with a young family, stage 4 cancer we hoped it was PE, but it's DIC

A day like any other Their son still needs to be picked up at school Instead we admit her to ICU no monitor, no lines, no need the unit clerk asks me to specify a diet "whatever she wants"

"So DAT?"

Husband sits by her side face worn as his faded jeans

I write orders for midazolam and dilaudid

She asks for lemonade

Do they sense the urgency?

We watch the mottling creep up her neck

There was no lemonade, just ginger ale

And a look shared between them I can't forget

I'm not sure they knew there were just moments it was just moments until her last breath of air

No code blue after all

She was made comfort care

\section{Chelsey Layne King}

Correspondence to Chelsey Layne King, Dalhousie University, Halifax, Nova Scotia B3H 4R2, Canada; chelsey.king@dal.ca

Acknowledgements Many thanks to Janet Barkhouse from Dalhousie Humanity-HEALS for her helpful edits, pushing my creative boundaries.

Competing interests None.

Provenance and peer review Not commissioned; externally peer reviewed.

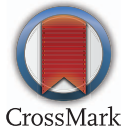

To cite King CL. Med Humanit 2015:41:e9.

Med Humanit 2015;41:e9. doi:10.1136/medhum-2015-010714 